\title{
Enrichment and purification of phenols from Callicarpa nudiflora Hook. et Arn by HP-20 macroporous resin
}

\author{
Xiaojie Yan ${ }^{1 a}$, Sheng Huang ${ }^{2,3}$, Fenglai $\mathrm{Lu}^{1}$, Zhixin $\mathrm{Gu}^{3}$, Lei Wang ${ }^{1}$, Yonglin \\ Huang ${ }^{1}$, Dianpeng $\mathrm{Li}^{1 \mathrm{~b}^{*}}$ \\ ${ }^{1}$ Guangxi Institute of Botany, Guangxi Zhuang Autonomous Region and the Chinese Academy of \\ Sciences, Guilin 541006, China; \\ 2Jiuzhitang CO., Ltd, Changsha 410021, China; Hainan Pharmaceutical Co., Ltd, Haikou 570311, \\ China; \\ ${ }^{3}$ Jiuzhitang CO., Ltd, Changsha 410021, China; \\ axiaojie128@126.com, ${ }^{\mathrm{b}} \mathrm{ldp} @ g x i b . c n$
}

Keywords: $C$. nudiflora; phenols; HP-20 macroporous resin

Abstract: Objective To study the technological parameters of the purification process of phenols from Callicarpa nudiflora (C. nudiflora) with HP-20 macroporous resin.Methods The kinetic adsorption and desorption experiments were carried out on HP-20 macroporous resin (HP-20) to optimize the separation process of phenols. Additionally, the effects of four parameters including adsorption flow rate, elute flow rate, volume of $10 \%$ ethanol and $50 \%$ ethanol solution for elution were explored by a L4/3 orthogonal experiment. Finally, content of phenols in samples before and after being treated by HP-20 were compared. Results The results showed that a good separation and purification of crude total phenols extract from $C$. nudiflora was achieved using HP-20. The optimum conditions were found to be: initial concentration of $50 \mathrm{mg} \cdot \mathrm{mL}^{-1}$, absorb flow rate of $1 \mathrm{~mL} \cdot \mathrm{min}^{-1}$, elute flow rate of $3 \mathrm{~mL} \cdot \mathrm{min}^{-1}, 5 \mathrm{BV}$ of $10 \%$ ethanol solution for prewash and $10 \mathrm{BV}$ of $50 \%$ ethanol solution for desorption solvent. Conclusion The content of phenols is above $40 \%$ in $C$. nudiflora after being treated by HP-20, indicating that HP-20 could be successfully applied to enrich and purify phenols in $C$. nudiflora.

\section{Introduction}

Luo Hua zi zhu (C. nudiflora) is belong to Verbenaceae family, which is also called zizhu, ganfengchai, baihuacha, fantangye, dayebanjiu, xiyebanjiuhua and so on. It is widely distributed in the south of China, such as Hainan, Guangxi and Guangdong province, especially in Hainan province. In addition, it has also been widely planted in the country of India, Vietnam and Malaysia ${ }^{[1-3]}$. It tastes bitter, slightly acrid and moderate. Owing to the effects on anti-inflammatory detoxification and convergence bleeding, it is commonly used to treat purulent inflammation, acute infectious hepatitis, burns, scald, traumatic hemorrhage and other diseases. The chemical compositions of $C$. nudiflora are complicated, mainly including flavonoids, tannins, phenolic acid, polysaccharide and other compounds. The phenolic acids significantly shorten the part activated clotting time live enzymes activity of pharmacological effects, so the composition may be the $C$. nudiflora hemostatic function of main active ingredient ${ }^{[4-7]}$.

\section{Experiments}

\section{Experimental materials}

C. nudiflora dry extract powder, hereinafter referred to as the dry extract, provided by the jiu zhi tang Hainan Pharmaceutical Co., Ltd. Its batch number was 110500. All chemicals and regents used in the experiments were of analytical grade.

HP-20 was purchased from Mitsubishi chemical corporation (Japan). The resin was soaked with $95 \%$ ethanol for $24 \mathrm{~h}$ to swell adequately. Subsequently the resin was eluted by $95 \%$ ethanol until white casse disappeared when the eluting reagent was mixed with pure water $(1: 5, \mathrm{~V} / \mathrm{V})$, and then the resin was washed with pure water until the liquor had no alcoholic odor ${ }^{[8]}$. 


\section{Experimental methods}

\section{Determination of phenols content by UV spectrophotometry}

Gallic acid was employed as a standard compound to determine the content of phenols by UV spectrophotometry in this study. The working curve of gallic acid was: $y=30.223 x+0.011(n=7, r=$ $0.9992,0.0000 \sim 0.0240 \mathrm{mg} \cdot \mathrm{mL}^{-1}$, detective wavelength of $760 \mathrm{~nm}$ ), where y is absorbance of the tested sample and $\mathrm{x}$ is concentration of the tested sample.

\section{Kinetic absorption and desorption tests}

The Kinetic-Tandem assay was employed to investigate kinetic adsorption capacity of HP-20. The assay was performed as follows: The experiment was carried out in a glass column $(25 \mathrm{~mm} \times 500 \mathrm{~mm})$ wet packed with the HP-20. The bed volume (BV) of the resin was $20 \mathrm{~mL} .500 \mathrm{~mL}$ sample solution (the initial concentration was $10 \mathrm{mg} \cdot \mathrm{mL}^{-1}$ ) flowed through the column at the flow rate of $2 \mathrm{~mL} \cdot \mathrm{min}^{-1}$. The content of phenols $\left(\mathrm{C}_{1}\right)$ in elution $\left(\mathrm{E}_{1}\right)$ was detected by UV analysis when the sample solution drained away through the column. Subsequently the elution flowed through the column again at the same flow rate. Concentration of phenols $\left(\mathrm{C}_{2}\right)$ in elution $\left(\mathrm{E}_{2}\right)$ was analyzed. Repeated the above steps until $\mathrm{C}_{\mathrm{n}+1}$ changed little comprised with $\mathrm{C}_{\mathrm{n}}$. At this moment the kinetic absorption can be seen reaching the equilibrium point. Then kinetic absorption mass of HP-20 was calculated ${ }^{[8]}$.

Five sample solutions with different initial concentrations $\left(10,20,30,40\right.$ and $\left.50 \mathrm{mg} \cdot \mathrm{mL}^{-1}\right)$ were employed to investigate effect of the initial concentration of sample solution on the enrichment and purification process. The seven samples were dealt with same parameters including sample quality, absorb flow rate, elute flow rate and so on. These experiments were carried out in seven pillars of glass $(20 \mathrm{~mm} \times 500 \mathrm{~mm})$ wet packed with the HP-20. The BV of the resins were $15 \mathrm{~mL}$. The kinetic absorption capacities were compared when the absorb processes were finished ${ }^{[8]}$.

The experiment was carried out in a glass column $(25 \mathrm{~mm} \times 500 \mathrm{~mm})$ wet packed with the HP-20. The BV of the resin was $20 \mathrm{~mL}$. The resin column that reached absorb equilibrium was used to do kinetic desorption tests based on a gradient elution program. The column was eluted by pure water, $10 \%$ ethanol, $30 \%$ ethanol, $50 \%$ ethanol, $70 \%$ ethanol, $80 \%$ ethanol for $5 \mathrm{BV}$, respectively, at a flow rate of $2 \mathrm{~mL} \cdot \mathrm{min}^{-1}$. The concentration of phenols in desorption solution collected at $1 \mathrm{BV}$ internals was monitored $^{[8]}$.

\section{L4/3 orthogonal experiment}

In order to fully study the best parameters in process of purification of phenols by HP-20, L4/3 orthogonal experiment were performed in nine pillars of glass $(20 \mathrm{~mm} \times 500 \mathrm{~mm})$. The BV of the resins were $15 \mathrm{~mL}$. The parameters to be tested and their values are listed in Table 1. After each test was finished, the yield mass of extract, yield mass of phenols, yield ratio and content of phenols were investigated ${ }^{[8]}$.

Table 1 The parameters tested in the orthogonal experiment

\begin{tabular}{cccc}
\hline $\begin{array}{c}\text { Absorb flow } \\
\text { rate } \\
\left(\mathrm{mL} \cdot \mathrm{min}^{-1}\right)\end{array}$ & $\begin{array}{c}\text { Elute flow } \\
\text { rate } \\
\left(\mathrm{mL} \cdot \mathrm{min}^{-1}\right)\end{array}$ & $\begin{array}{c}\text { Volume of } 10 \% \text { ethanol } \\
\text { for prewash } \\
(\mathrm{BV})\end{array}$ & $\begin{array}{c}\text { Volume of } 50 \% \text { ethanol solution for } \\
\text { desorption solvent } \\
(\mathrm{BV})\end{array}$ \\
\hline 1 & 2 & 3 & 3 \\
2 & 3 & 5 & 5 \\
4 & 4 & 7 & 10 \\
\hline
\end{tabular}

\section{Verification tests}

In order to validation the best parameters in process of purification of phenols by HP-20. Three verification tests were performed in three pillars of glass $(20 \mathrm{~mm} \times 500 \mathrm{~mm})$. The BV of the resins were $15 \mathrm{~mL}$. After each test was finished, the yield mass of extract, yield mass of phenols, yield ratio, content of phenols, average of phenols content and RSD were investigated. 


\section{Results and Discussion}

\section{Absorption and desorption kinetics}

In our study, the kinetic-Tandem absorption test was carried out to determine the maximum absorption capacity when the HP-20 resin reached the equilibrium point in kinetic process. The capacity of adsorption is calculated as follows. Adsorption capacity: $\mathrm{Q}=\left(\mathrm{C}_{0}-\mathrm{C}_{\mathrm{e}}\right) * \mathrm{~V}_{0} / \mathrm{V}$. where $\mathrm{Q}$ is the adsorption capacity, which represents the mass of adsorbate adsorbed on $1 \mathrm{~mL}$ wet resins at adsorption equilibrium; $\mathrm{C}_{0}$ and $\mathrm{C}_{\mathrm{e}}$ is the initial and equilibrium concentration of phenols in the sample solutions, respectively; $\mathrm{V}_{0}$ is the initial volume of sample solution, and $\mathrm{V}$ is the volume of the wet resins. According to the dates shown in Table 2, after thirdly tandem absorption process, the resins reached its equilibrium point in kinetic absorption process. The maximum absorption capacity was calculated as $30.6058 \mathrm{mg} /$ ( $1 \mathrm{~mL}$ wet resins), which can be used to determine the volume of HP-20 on the basis of the mass of sample.

Table 2 The result of absorption capacity in the Kinetic-Tandem assay

\begin{tabular}{cccccc}
\hline $\begin{array}{c}\text { Count of } \\
\text { tandom }\end{array}$ & $\begin{array}{c}\text { Reaction } \\
\text { volume } \\
(\mathrm{mL})\end{array}$ & $\begin{array}{c}\mathrm{A} \\
(760 \mathrm{~nm})\end{array}$ & $\begin{array}{c}\text { The total } \\
\text { phenol } \\
\text { content in } \\
\text { the reaction } \\
(\mathrm{mg})\end{array}$ & $\begin{array}{c}\text { The total } \\
\text { phenol } \\
\text { concentration } \\
\left(\mathrm{mg} \cdot \mathrm{mL}^{-1}\right)\end{array}$ & $\begin{array}{c}\text { Absorption } \\
\mathrm{mass}\left(\mathrm{mg} \cdot \mathrm{mL}^{-1}\right)\end{array}$ \\
\hline 0 & 0.005 & 0.249 & 0.0079 & 1.5750 & -- \\
1 & 0.05 & 0.480 & 0.0155 & 0.3104 & 31.6150 \\
2 & 0.05 & 0.560 & 0.0182 & 0.3633 & 30.2915 \\
3 & 0.05 & 0.541 & 0.0175 & 0.3507 & 30.6058 \\
4 & 0.05 & 0.541 & 0.0175 & 0.3507 & 30.6058 \\
5 & 0.05 & 0.541 & 0.0175 & 0.3507 & 30.6058 \\
\hline
\end{tabular}

In order to investigate the initial concentration of loading sample solution, five concentrations (10, 20, 30, 40 and $50 \mathrm{mg} \cdot \mathrm{mL}^{-1}$ ) of sample solution were selected. Shown in Fig. 1, when initial concentration has changed from 10 to $50 \mathrm{mg} \cdot \mathrm{mL}^{-1}$, the absorption capacities did not increase significantly. At the same time, taking into account factors such as sample on solubility and time, 50 $\mathrm{mg} \cdot \mathrm{mL}^{-1}$ was chosen to be initial concentration of the sample solution.

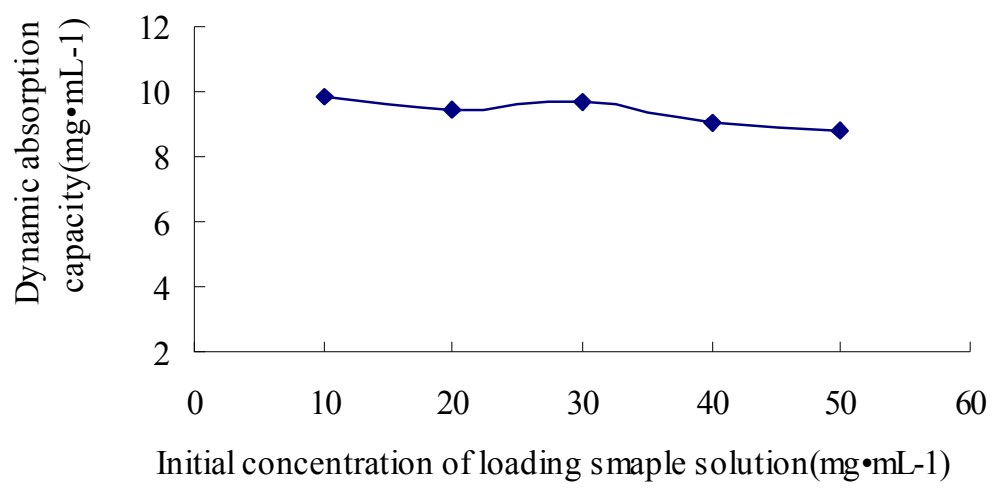

\section{Fig.1 The effect of initial concentration of loading sample solution on kinetic absorption capacity}

The kinetic desorption curve on HP-20 was obtained based on a gradient elution program. As depicted in fig. 2, the phenols absorbed by HP-20 were desorbed almost completely after eluted by $30 \%$ and $50 \%$ ethanol. Hence, the appropriate and economic ethanol concentration of elution solution can be optimized as $50 \%$. 


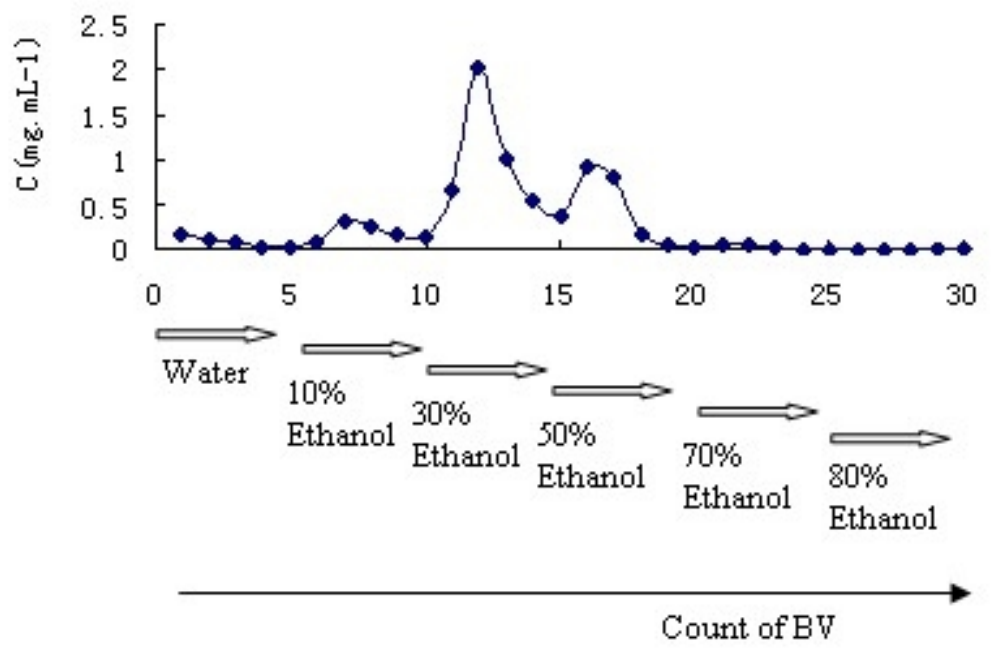

Fig.2 The kinetic desorption curve based on the gradient elution program

\section{The optimization of parameters by orthogonal experiment}

According table 3 and 4 the parameters of absorb flow rate, elute flow rate, volume of $10 \%$ ethanol for prewash and volume of $50 \%$ ethanol solution for desorption solvent were optimized as $1 \mathrm{~mL} \cdot \mathrm{min}^{-1}, 3$ $\mathrm{mL} \cdot \mathrm{min}^{-1}, 5 \mathrm{BV}$ and $10 \mathrm{BV}$, respectively. Furthermore, among these four parameters, volume of 50\% ethanol solution for desorption solvent and volume of $10 \%$ ethanol solution for prewash were important factors in the enrichment and purification process of phenols in $C$. nudiflora according to Rj.

Table 3 Results of the orthogonal experiment

\begin{tabular}{cccc}
\hline Order & $\begin{array}{c}\text { Yield mass of extract } \\
(\mathrm{mg})\end{array}$ & $\begin{array}{c}\text { Yield mass of phenols } \\
(\mathrm{mg})\end{array}$ & $\begin{array}{c}\text { Content of phenols } \\
(\%)\end{array}$ \\
\hline 1 & 255.6 & 68.2 & 26.68 \\
2 & 241.6 & 90.3 & 37.39 \\
3 & 295.1 & 107.5 & 36.41 \\
4 & 333.9 & 116.4 & 34.86 \\
5 & 209.3 & 66.9 & 31.94 \\
6 & 288.1 & 93.6 & 32.47 \\
7 & 265.2 & 90.1 & 33.97 \\
8 & 331.0 & 110.7 & 33.44 \\
9 & 194.3 & 63.3 & 32.57 \\
\hline
\end{tabular}

Table 4 Analysis of the orthogonal experiment on the basis of content of phenols in $C$. nudiflora

\begin{tabular}{ccccc}
\hline & $\begin{array}{c}\text { Absorb flow } \\
\text { rate } \\
\left(\mathrm{mL} \cdot \mathrm{min}^{-1}\right)\end{array}$ & $\begin{array}{c}\text { Elute flow rate } \\
\left(\mathrm{mL} \cdot \mathrm{min}^{-1}\right)\end{array}$ & $\begin{array}{c}\text { Volume of } 10 \% \\
\text { ethanol for prewash } \\
(\mathrm{BV})\end{array}$ & $\begin{array}{c}\text { Volume of } 50 \% \text { ethanol solution } \\
\text { for desorption solvent } \\
(\mathrm{BV})\end{array}$ \\
\hline $\mathrm{Kj} .1$ & 33.49 & 31.84 & 30.86 & 30.40 \\
$\mathrm{Kj} .2$ & 33.09 & 34.26 & 34.94 & 34.61 \\
$\mathrm{Kj} .3$ & 33.33 & 30.72 & 34.49 & 34.90 \\
$\mathrm{Rj}$ & 0.4 & 3.54 & 4.08 & 4.50 \\
\hline
\end{tabular}

The results of the Optimum conditions experiment

As listed in Table 5. There was good agreement among the three parallel experiments. After dealt by the optimal enrich and purify process on HP-20, the content of phenols in the sample is increased from $15.75 \%$ to $41.29 \%$. 
Table 5 Results of the Optimum conditions experiment

\begin{tabular}{cccccc}
\hline Order & $\begin{array}{c}\text { Yield mass } \\
\text { of extract } \\
(\mathrm{mg})\end{array}$ & $\begin{array}{c}\text { Yield mass } \\
\text { of phenols } \\
(\mathrm{mg})\end{array}$ & $\begin{array}{c}\text { Content of } \\
\text { phenols } \\
(\%)\end{array}$ & $\begin{array}{c}\text { The average } \\
(\%)\end{array}$ & RSD(\%) \\
\hline 1 & 310.6 & 129.1 & 41.56 & 41.29 & 3.70 \\
2 & 317.5 & 125.9 & 39.65 & & \\
\hline 3 & 308.2 & 131.5 & 42.67 & & \\
\hline
\end{tabular}

\section{Conclusion}

In our study, the enrichment and purification process of phenols in $C$. nudiflora with HP-20 has been successfully developed. Our study showed that under the optimized conditions, i.e. initial concentration of $50 \mathrm{mg} \cdot \mathrm{mL}^{-1}$, absorb flow rate of $1 \mathrm{~mL} \cdot \mathrm{min}^{-1}$, elute flow rate of $3 \mathrm{~mL} \cdot \mathrm{min}^{-1}, 5 \mathrm{BV}$ of $10 \%$ ethanol solution for prewash and $10 \mathrm{BV}$ of $50 \%$ ethanol solution for desorption solvent, content of phenols in $C$. nudiflora was increased significantly after dealt by HP-20 according to UV spectrophotometry comparison. In conclusion, the result of our study suggested that macroporous resin adsorption method was applied successfully to enrich and purify phenols in $C$. nudiflora.

\section{Acknowledgements}

This work received support from the Bagui Scholar Program of the Guangxi Institute of Botany, Guilin (The third batch), the National science and technology (SQ2010BAJY1411-07-05), the TCM modernization special project of Hainan province (2012ZY020), the Scientific Research and Techonology Development Program of Guangxi (11107010-3-10) and the director of capital projects of Guangxi Key Laboratory of Functional Phytochemicals Research and Utilization (ZRJJ2015-14).

\section{References}

[1] Yang Dan, Zhongzhi Qian, Yanze Liu, et al. J.Chin Herb Med. Vol. 2(2010), P.272 288

[2] Lin Dong, Mingsheng Liu, Jinhui Wang. J.Chin Med Chem. Vol. 19(2009), P.371(In Chinese)

[3] Feipeng Gao, Hao Wang, Wencai Ye, et al. J. Chin Pharm Univ. Vol. 41(2010), P.120 123 (In Chinese)

[4] William P Jones, A Douglas Kinghorn. J.Curr Bioact Compd. Vol. 4(2008), P.15 32

[5] WenLi Mei, Zhuang Han, HaiBin Cui, et al. J. Nat Prod Res. Vol. 24(2010), P.899 904

[6] Jijun Liang, Jinlong Qi, Li Li, et al.Chem Nat Comp. Vol. 47(2011), P.110

[7] Jie Zhang, Baoquan Li, Feng Feng, et al. J. Chin Mat Med. Vol. 35(2010), P.3297 3301 (In Chinese)

[8] Han Wei, Jinlan Ruan, Yongfang Lei, et al. J. Chin Nat Med. Vol. 10(2012), P.119 124 